\title{
CÓMO LAS LEYES DE INMIGRACIÓN DE LOS ESTADOS UNIDOS PERMITEN LA ESCLAVITUD MODERNA
}

Giuliana Belissa Urrelo Huapaya*

* Abogada de la Universidad Femenina del Sagrado Corazón. Estudiante del Programa L.L.M. de la Escuela de Derecho Elisabeth Haub en la Universidad de Pace.Paralegal de Inmigración en casos de visas VAWA y $U$ para víctimas de delitos en la organización Make The Road New York. 


\title{
CÓMO LAS LEYES DE INMIGRACIÓN DE LOS ESTADOS UNIDOS PERMITEN LA ESCLAVITUD MODERNA
}

\author{
Giuliana Belissa Urrelo Huapaya
}

\begin{abstract}
RESUMEN
La trata de personas es posiblemente uno de los delitos transnacionales más rentables en la actualidad. Aunque la esclavitud fue abolida en los Estados Unidos con la aprobación de la Decimotercera Enmienda en 1865, la práctica de vender y explotar la voluntad de los seres humanos continúa ocurriendo. De hecho, en el año 2000, Estados Unidos promulgó la Ley de protección a las víctimas de trata y violencia, la cual prohíbe tanto el tráfico sexual como el tráfico laboral. A pesar de los esfuerzos concertados para combatir la trata de personas, el comercio de personas continúa creciendo y, si bien la Ley de protección contra la trata y la violencia es una mejora con respecto a las políticas anteriores, solo una fracción de las víctimas estimadas recibe asistencia a sus necesidades. Este artículo explorará el problema de la trata de personas en los Estados Unidos y cómo las políticas de inmigración existentes permiten que la trata persista en los Estados Unidos.
\end{abstract}

\section{PALABRAS CLAVE}

Trata de Personas, Esclavitud Moderna, Ley de Protección de Víctimas, Políticas de Inmigración

\section{INTRODUCCIÓN}

El término "trata de personas" abarca violaciones de derechos laborales y civiles que son una forma moderna de esclavitud. Debido a que la forma moderna de tráfico ha sido regulada por menos de una década, los conceptos aún son poco conocidos. Los recursos para las personas que son víctimas de tráfico, mientras crecen, siguen siendo limitados y las víctimas de trata se encuentran entre los tipos de víctimas más aislados. ${ }^{1}$

La trata de personas es un fenómeno de magnitud global que viola los derechos humanos de millones de mujeres y niños. Las víctimas de trata de personas están sujetas a la fuerza, el fraude o la coacción con fines de explotación sexual o trabajo forzoso. A menudo, la raza, el origen étnico, el género, la clase o el estado de un individuo en su país de origen los hace más vulnerables a los traficantes.

La parte I de este artículo proporcionará una descripción general y antecedentes de la trata de personas y las leyes fundamentales y las protecciones legales, como los tratados internacionales, las convenciones y las leyes internacionales consuetudinarias promulgadas para proteger a las víctimas de trata de personas.

La Parte II explorará cómo las políticas y procedimientos implementados por el gobierno de los Estados Unidos pueden no estar en el mejor interés de las víctimas, y analizará el tema de la trata de personas y las implicaciones de las políticas de inmigración en las leyes de protección para las víctimas de trata.

La Parte III evaluará los alivios migratorios y los recursos disponibles para ayudar a las víctimas de este crimen atroz. Esta parte notará que la presencia continua proporciona ayuda migratoria temporal a las víctimas de trata para permitirles permanecer legalmente en los Estados Unidos para procesar a sus traficantes, a fin de obtener una visa para permanecer en el país.

Carole, Angel and Orloff, Lesley. Trafico Humana y Visa T NIWAP. Recuperada de http://library.niwap.org/wp-content/ uploads/2015/IMM-Man-Ch11-TraffickingTVisa.pdf 


\section{Una Visión General de la Trata de Personas}

Aunque Brasil fue el último país del mundo en abolir la esclavitud (en 1988), se ha desarrollado una nueva forma de esclavitud: la trata de personas, también conocida como esclavitud moderna, la cual ha recibido recientemente una consideración importante en los círculos globales. La globalización y las tendencias migratorias transnacionales continúan ampliando las disparidades económicas y aumentando la vulnerabilidad de las poblaciones oprimidas a diferentes formas de trata de personas. La mayoría de las víctimas de trata de personas son generalmente explotadas con fines laborales o sexuales. Las personas más vulnerables a la trata de personas son generalmente los pobres, los marginados y las personas que buscan oportunidades de empleo. Tres tipos principales de trata de personas en la actualidad son el tráfico laboral, el tráfico sexual y la esclavitud. ${ }^{2}$

La trata de personas es una catástrofe humana en expansión, a menudo relacionada con el crimen organizado transnacional. La trata de personas es una violación de los derechos humanos fundamentales y la delincuencia económica. La trata de personas es una conducta criminal contraria a los mercados laborales libres y justos, lo que afecta la capacidad de las empresas para competir éticamente por bienes, servicios y mano de obra, lo cual socava el desarrollo económico legítimo de las empresas, el gobierno y los países en desarrollo, y extrae beneficios exorbitantes a los mercados criminales y grises.

La Organización Internacional del Trabajo (OIT) ha estimado que, en un período de diez años, 20,9 millones, aproximadamente tres de cada mil personas en todo el mundo, han sido víctimas de trabajo forzado o explotación sexual. Un creciente grupo de organismos internacionales, gobiernos nacionales, empresas y organizaciones no gubernamentales están comprometidos con la erradicación de la trata de personas. Estos incluyen las Naciones Unidas (ONU), la Unión Europea (UE) y los Estados Unidos.

\section{1. ¿Qué es la Esclavitud Moderna?}

El Artículo 3 (a) del Protocolo para Prevenir, Suprimir y Sancionar la Trata de Personas Especialmente Mujeres y Niños (Protocolo de Trata) define la Trata de Personas como:

El reclutamiento, transporte, traslado, refugio o recepción de personas, mediante la amenaza o el uso de la fuerza u otras formas de coacción, de secuestro, de fraude, de engaño, de abuso de poder o de posición de vulnerabilidad o de la entrega o recepción de pagos o beneficios para lograr el consentimiento de una persona que tiene control sobre otra persona, con el propósito de explotación. La definición de trata de personas, tal como se describe en el Protocolo de Trata, tiene tres componentes principales: ${ }^{3}$

- La Acción, que significa el reclutamiento, transporte, traslado, refugio o recepción de personas;

- Los Medios, que incluyen amenaza o uso de la fuerza, engaño, coerción, abuso de poder o posición de vulnerabilidad; y

- El Propósito, que siempre es explotación. El artículo 3 del Protocolo contra la trata dice que la explotación "incluirá, como mínimo, la explotación de la prostitución ajena u otras formas de explotación sexual, trabajo o servicios forzados, esclavitud o prácticas similares a la esclavitud, la servidumbre o la extracción de órganos". ${ }^{4}$

\footnotetext{
Weiss, Marley S. (2015) Human Trafficking and Forced Labor: A Primer, 1. pp 31. ABA Journal Lab. \& Emp. Law 1 Oficina de las Naciones Unidas contra la Droga y el Delito, Trata de Personas. Recuperada de www.unodc.org/unodc/ en/human-trafficking/what-is-human-trafficking.html

4 Convención de las Naciones Unidas contra la Delincuencia Organizada Transnacional y sus Protocolos (Nueva York, 2014). Recuperada de https://www.unodc.org/documents/treaties/UNTOC/Publications/TOC\%20Convention/ TOCebook-e.pdf
} 
Este Protocolo sobre la trata de personas fue adoptado por la Resolución 55/25 de la Asamblea General, y entró en vigor el 25 de diciembre de 2003. Es el primer instrumento global jurídicamente vinculante con una definición acordada sobre la trata de personas. La intención detrás de esta definición es facilitar la convergencia en los enfoques nacionales con respecto al establecimiento de delitos penales internos que respaldarían la cooperación internacional eficiente en la investigación y el procesamiento de casos de trata de personas. Un objetivo adicional del Protocolo es proteger y ayudar a las víctimas de trata de personas con pleno respeto de sus derechos humanos. ${ }^{5}$

\section{El Problema del Tráfico Mundial}

La trata de personas es el crimen de más rápido crecimiento en el mundo que debe abordarse con un enfoque integral, tanto a nivel nacional como internacional. Los pasos principales deben incluir la sensibilización sobre el tema y abordar las causas fundamentales de la trata de personas, la introducción de legislación que penalice la trata de personas, la aplicación adecuada y los mecanismos de revisión, y la asistencia adecuada a las víctimas. ${ }^{6}$

La trata de personas es un problema global, que afecta a las vidas de millones de personas en todo el mundo y les roba su dignidad. Los traficantes engañan a mujeres, hombres y niños de todos los rincones del mundo y los obligan a situaciones de explotación todos los días. Si bien la forma más conocida de trata de personas es con fines de explotación sexual, cientos de miles de víctimas son víctimas de trata con fines de trabajo forzado, servidumbre doméstica, mendicidad. A nivel mundial, una de cada cinco víctimas de trata de personas son niños, aunque en las regiones y subregiones más pobres, como África, constituyen la mayoría de las personas objeto de trata. Mientras tanto, las mujeres representan dos tercios de las víctimas de la trata de personas en el mundo.

Además, el informe de la OIT: Beneficios y pobreza: La economía del trabajo forzoso indica que:

Dos tercios del total estimado de US \$ 150 mil millones, o US \$ 99 mil millones, provinieron de la explotación sexual comercial, mientras que otros US \$ 51 mil millones se debieron a la explotación económica forzada, incluido el trabajo doméstico, la agricultura y otras actividades económicas. El desglose de los beneficios generados por la explotación económica forzada es el siguiente:

- US \$ 34 mil millones en construcción, manufactura, minería y servicios públicos

- US \$ 9 mil millones en agricultura, incluida la silvicultura y la pesca.

- US \$ 8 mil millones ahorrados por hogares privados al no pagar o pagar de menos a los trabajadores domésticos en trabajos forzados.

Dicho esto, para hacer un cambio significativo en la vida de las personas víctimas del trabajo forzoso, se necesita una acción concreta e inmediata. Lo cual significa que los gobiernos tienen que trabajar para fortalecer la ley, la política y su aplicación con los empleadores para fortalecer su diligencia debida contra el trabajo forzoso, incluso en sus cadenas de suministro, y con los sindicatos para representar y capacitar a los que están en riesgo.

\section{Instrumentos Internacionales relativos a la Trata de Personas.}

El derecho internacional es un conducto poderoso para combatir la trata de personas. Los instrumentos más reputados del derecho internacional que han marcado el camino para definir, prevenir y procesar la trata de personas son los siguientes: ${ }^{7}$

5 Convención de las Naciones Unidas contra la Delincuencia Organizada Transnacional y sus Protocolos. Recuperada de https://www.unodc.org/unodc/en/organized-crime/intro/UNTOC.html

6 Ochab, Ewelina U. El crimen de más rápido crecimiento en el mundo. Recuperada de https://www.forbes.com/sites/ ewelinaochab/2017/07/29/the-worlds-fastest-growingcrime/2/\#3d7c6ee06547

7 Oficina del Alto Comisionado de Derechos Humanos de las Naciones Unidas, Instrumentos Internacionales de Trata de Personas. Recuperada de http://www.ohchr.org/Documents/lssues/Women/WRGS/OnePagers/ IntInstrumentsconcerningTraffickingpersons_Aug2014.pdf 
i. El Protocolo de Palermo, un suplemento de la Convención de las Naciones Unidas contra la Delincuencia Organizada Transnacional (2000). El artículo 5 del Protocolo requiere que los Estados penalicen el tráfico, el intento de tráfico y cualquier otra participación u organización intencional en un esquema de tráfico.

ii. Dos convenios de la Organización Internacional del Trabajo (OIT) se centran en el trabajo o los servicios forzados: el Convenio de la OIT sobre el trabajo forzoso (Convenio núm. 29 de 1930) y su nuevo Protocolo adoptado, que define el trabajo forzoso u obligatorio, y el Convenio de la OIT sobre la abolición del trabajo forzoso (Convenio núm. 105 de 1957).

iii. La Convención sobre la Esclavitud (1926), que define la esclavitud, y su Convención Suplementaria que describe "prácticas similares a la esclavitud", incluida la servidumbre por deudas.

iv. La Convención de las Naciones Unidas para la Supresión del Tráfico de Personas y de la Explotación de la Prostitución de Otros (1949), que exige a los Estados castigar a cualquier persona que explote la prostitución de otro.

v. El Pacto Internacional de Derechos Civiles y Políticos, que prohíbe una serie de prácticas directamente relacionadas con la trata, incluida la esclavitud, el comercio de esclavos, la servidumbre y el trabajo forzoso.

vi. La Convención sobre la eliminación de todas las formas de discriminación contra la mujer, que obliga a los Estados a tomar todas las medidas apropiadas para reprimir todas las formas de trata de mujeres. La Recomendación general No. 19 identifica la trata como una forma de violencia contra las mujeres porque pone a las mujeres en un riesgo especial de violencia y abuso. La trata de personas es incompatible con el disfrute equitativo de los derechos por parte de las mujeres y con el respeto de sus derechos y dignidad.

\section{Trata de Personas en los Estados Unidos}

\section{Leyes Federales Actuales}

En las últimas dos décadas, el Congreso ha aprobado varios proyectos de ley integrales diseñados para atraer todo el poder y la atención del gobierno federal a la lucha contra la trata de personas. Las prohibiciones modernas de la trata de personas en los Estados Unidos tienen sus raíces en la Enmienda Trece a la Constitución de los Estados Unidos, que prohibió la esclavitud y la servidumbre involuntaria en 1865. Con la promulgación de la Ley de Protección de Víctimas de Trata de 2000 (TVPA), el Gobierno de los Estados Unidos se equipó con nuevas herramientas y recursos para organizar una campaña integral y coordinada para combatir la trata de personas con el fin de enjuiciar a los traficantes, proteger a las víctimas y prevenir el delito. Esta estrategia a menudo se denomina "3P", prevención, protección y procesamiento. Una cuarta "P", para la asociación, es un enfoque crucial que subraya los esfuerzos de este país contra la trata de personas. ${ }^{8}$

La TVPA del 2000 es la base de la legislación federal sobre la trata de personas y estableció varios métodos para procesar a los traficantes, prevenir la trata de personas y proteger a las víctimas y sobrevivientes de la trata. La ley establece que la trata de personas y los delitos conexos son delitos federales y les impone penas severas. También exige que se pague la restitución a las víctimas de la trata de personas. También trabaja para prevenir el tráfico al establecer la Oficina para monitorear y combatir el tráfico de personas, que debe publicar un informe de tráfico de personas cada año. Este informe describe y clasifica los esfuerzos de los países para combatir la trata de personas. El

8 Departamento de Justicia, Departamento de Salud y Servicios Humanos y Departamento de Seguridad Nacional, Plan de Acción Estratégico Federal sobre Servicios para Víctimas de Trata de Personas en los Estados Unidos 2013-2017 
TVPA de 2000 también estableció el Grupo de trabajo interinstitucional para monitorear y combatir el tráfico, que asiste en la implementación del TVPA. La TVPA del 2000 protege a las víctimas y sobrevivientes de la trata de personas al establecer la visa T, que permite a las víctimas de la trata de personas, y que sus familias se conviertan en residentes temporales de los Estados Unidos y sean elegibles para convertirse en residentes permanentes después de tres años. ${ }^{9}$

Desde 2000, el Congreso mantuvo el apoyo a este marco al volver a autorizar TVPA de 2000 cuatro veces, en 2003, 2005, 2008 y 2013 de la siguiente manera:

La Ley de protección de las víctimas de la trata de personas de 2003 (TVPRA de 2003) estableció un derecho de acción federal y civil para que las víctimas de la trata de personas demanden a sus traficantes.

La Ley de Reautorización de Protección de Víctimas de Trata de 2005 (TVPRA de 2005) incluyó un programa piloto para albergar a menores que son sobrevivientes de trata de personas, y programas de subvención para ayudar a las autoridades estatales y locales a combatir la trata de personas. También amplió las medidas para combatir la trata internacionalmente, incluidas las disposiciones para combatir el turismo sexual, un programa piloto de $\$ 5$ millones para el tratamiento de las víctimas de trata en el extranjero y el fortalecimiento de la regulación sobre los contratos gubernamentales para garantizar que no se realicen con personas u organizaciones que promueven o participan en la trata de personas.

La Ley de Reautorización para la Protección de las Víctimas del Tráfico de 2008 (TVPRA de 2008) incluyó varias estrategias de prevención nuevas, que incluyen el requisito de que el gobierno proporcione información sobre los derechos de los trabajadores a todas las personas que solicitan visas de trabajo y educación. También puso en marcha nuevos sistemas para recopilar e informar datos sobre la trata de personas. Además de las estrategias de prevención, la reautorización de 2008 amplió las protecciones disponibles con la visa T, y exigió que todos los niños extranjeros no acompañados sean examinados como posibles víctimas de trata de personas. Esta reautorización también mejoró las sanciones penales contra los traficantes y amplió las definiciones de varios tipos de tráfico para facilitar el procesamiento.

La Ley de Reautorización de Protección de Víctimas de Trata de 2013 (TVPRA de 2013), que fue aprobada como una enmienda a la Ley de Violencia contra la Mujer, establece y fortalece los programas para garantizar que los ciudadanos estadounidenses no compren productos hechos por víctimas de trata de personas.

La Ley de Protección de Víctimas de la Trata de Personas se renovó por quinta vez el año pasado en septiembre de 2017. Este proyecto fue aprobado en el Senado el 11 de septiembre de $2017^{10}$ y se remitió a la Subcomisión de Delitos, Terrorismo, Seguridad Nacional e Investigaciones el 22 de enero de 2018.

\section{Trata de Personas a Escala Nacional}

Cuando el tema de trata de personas atrajo la atención pública por primera vez en los Estados Unidos en la década de 1990, el debate se centró en la trata internacional de personas. En el año 2000, Estados Unidos aprobó una ley contra la trata de personas, popularmente llamada Ley de Protección de Víctimas de la Trata de Personas (TVPA), y las Naciones Unidas adoptó un tratado contra la trata de personas llamado Protocolo de Palermo. Tanto la TVPA como el Protocolo de

9 Proyecto Polaris, leyes federales vigentes. Recuperado de http://polarisproject.org/current-federal-laws

10 Resumen de acciones S.1311 - $115^{\circ}$ Congreso. Recuperado de https://www.congress.gov/bill/115th-congress/senatebill/1311/actions 
Palermo se enfocaron en combatir la trata internacional de personas al alentar a los países de todo el mundo a aprobar leyes contra la trata y enjuiciar a los traficantes. ${ }^{11}$

Sin embargo, a pesar de los esfuerzos para combatir el creciente problema de trata de personas, la esclavitud moderna sigue creciendo. Cada año, los traficantes de personas generan miles de millones de dólares en ganancias al victimizar a millones de personas en los Estados Unidos y en todo el mundo. A pesar de la creciente conciencia acerca de este crimen, la trata de personas continúa sin reportarse debido a sus ideas erróneas acerca de su definición y la falta de conocimiento sobre sus indicadores.

Si bien, no hay una estimación oficial del número total de víctimas de trata de personas en los EE. UU. Polaris, una organización de servicios, investigación y defensa contra la trata de personas con sede en los Estados Unidos en Washington, DC, estima que la cantidad total de víctimas a nivel nacional llega a cientos de miles cuando se agregan las estimaciones de adultos y menores y el tráfico sexual y laboral. Además, la línea directa nacional de tráfico de personas indica que más de 40,000 casos totales de tráfico de personas han sido reportados a la línea directa en los últimos 10 años. La línea directa recibe anualmente múltiples informes de casos de trata de personas en cada uno de los 50 estados y D.C con un promedio de 90 llamadas por día. ${ }^{12}$

3. Implicaciones de las Políticas de Inmigración en las Leyes de Protección para las Víctimas de Tráfico de Personas

A pesar de la legislación que castiga a los traficantes y proporciona servicios y asistencia a las víctimas, la trata de personas continúa existiendo en los Estados Unidos. Una reforma legal a la aplicación de las protecciones laborales y de inmigración existentes reforzarían los esfuerzos actuales para abordar la trata.

En este sentido, exigir un mayor cumplimiento de las protecciones existentes de los trabajadores. Muchos trabajadores en comunidades vulnerables a la trata de personas están protegidos por leyes laborales federales y estatales que establecen salarios mínimos, requieren medidas de seguridad, prohíben la discriminación y protegen el derecho a organizarse para mejores condiciones de trabajo. Una aplicación mayor y más generalizada de estas protecciones legales en tales comunidades reduciría la vulnerabilidad de los trabajadores a la trata y otras formas de explotación.

De otro lado, la protección a los inmigrantes indocumentados de trata de personas. Los inmigrantes indocumentados son extremadamente vulnerables a la trata de personas por temor a la deportación. Las leyes actuales extienden la mayoría de las protecciones laborales a los inmigrantes indocumentados. Sin embargo, desconocedores de sus derechos y muchas veces temerosos de las consecuencias de intentar buscar ayuda, estos trabajadores permanecen extremadamente vulnerables y aislados.

En este sentido, la administración actual se idealiza a sí misma como una administración de "ley y orden", pero desafortunadamente sus políticas de inmigración han dado prioridad a la deportación eventualmente de inmigrantes que han sido víctimas de tráfico humano. Debido a estas políticas, muchos temen, con razón, que tengan un efecto negativo en la lucha contra el tráfico y la protección de las víctimas. Los expertos advierten que la trata se disparará bajo esta administración actual, ya que el temor a la deportación aprovecha el poder de los traficantes sobre las víctimas, hace que las víctimas estén menos dispuestas a presentarse, y empuja el crimen más a la clandestinidad. Otros expertos sugieren que incluso las opciones de visa existentes bajo la ley TVPA no son suficientes

11 Barker, Carrie N. La influencia de la trata internacional de personas en las leyes de prostitución de los Estados Unidos: el caso de las leyes de expulsión. Recuperado de http://lawreview.syr.edu/wp-content/uploads/2013 /03/K-Baker.pdf

12 Proyecto Polaris, Los hechos. Recuperado de http://polarisproject.org/human-trafficking/facts 
para proteger a las víctimas de trata, ya que su emisión depende de la discreción del sistema de inmigración, el cual es extremadamente hostil.

De hecho, considero que es correcto señalar que las políticas de inmigración actuales tienen implicaciones negativas para las víctimas de trata, sin embargo, pocos proponen soluciones concretas a estos problemas. Dado que la administración de "ley y orden" no da ninguna indicación de voluntad para revertir estas políticas, el movimiento contra la trata necesita desesperadamente soluciones constructivas y críticas para presionar a la actual administración sobre el tema de la protección de las víctimas de trata de personas.

Tres soluciones clave para detener y revertir el impacto negativo de estas políticas son las siguientes: primero, aprovechar las protecciones que existen según las leyes actuales, como TVPA, para responsabilizar a la actual administración el garantizar la protección a las víctimas de trata; segundo, capacitar a las personas encargadas de hacer cumplir la ley de inmigración a fin de difundir el conocimiento de las leyes existentes y garantizar protección a las víctimas, en lugar de criminalizarlas; y tercero, promulgar una nueva propuesta que amplíe la protección de las víctimas en los Estados Unidos.

A pesar de que las actuales políticas de inmigración son peligrosas y pueden empujar a las víctimas a la sombra, es evidente que también brindan la oportunidad para que los defensores aprovechen las leyes vigentes para presionar a la administración sobre el tema de la protección de víctimas y sobre el avance de prácticas que ayuden a las víctimas a escapar de situaciones de tráfico humano.

\section{Alcance de un caso de Tráfico Sexual en los Estados Unidos}

A continuacion se proporcionará un caso específico de estudio sobre la práctica del trabajo forzoso con el objetivo de aclarar qué tan real puede ser la esclavitud y la trata de personas hoy en día.

a. Caso: Residentes del estado de Nueva York contra G.M. ${ }^{13}$

(a quien en adelante llamaremos la víctima)

En 1989, la víctima, oriunda de la República Dominicana, conoció a su esposo mientras se encontraba con una visa de turismo en los Estados Unidos. La víctima decidió quedarse en los Estados Unidos con él, en parte, para ganar dinero para sus dos hijos que aún vivían en la República Dominicana. En 1994, decidieron casarse. Sin embargo, poco después, la relación empeoró cuando su esposo comenzó a abusar físicamente de la víctima, algo que nunca había sucedido antes del matrimonio. La víctima descubrió que su esposo era adicto a la cocaína, por lo que el abuso era a menudo más severo cuando él estaba bajo la influencia de las drogas. Su esposo la aisló de los demás y ejerció el control sobre casi todos los aspectos de su vida. Ella no estaba permitida a salir de la habitación o el apartamento sin él y él a menudo la dejaba y la recogía de sus trabajos, esperando en un automóvil estacionado afuera para asegurarse de que no fuera a otro lugar.

La víctima fue arrestada en seis ocasiones diferentes. Desde septiembre de 1997 hasta enero de 1998, ella fue arrestada dos veces por prostitución (Ley Penal § 230.00), dos veces por infracción penal en tercer grado (Ley Penal $\S 140.10$ ), y dos veces por posesión criminal de una sustancia controlada en el séptimo grado (Penal Ley $\S 220.03$ ). La víctima se declaró culpable en cada uno de estos casos, a menudo en las comparecencias, lo que resultó en dos condenas no penales por conducta desordenada, una violación y cuatro condenas por delitos menores clase B.

13 Ver el caso de Residentes de Estado de Nueva York v. G.M. 922 N.Y.S.2ed 761, 2011 N.Y. Slip Op. 21176 
Según la víctima, su esposo la obligó a participar en estas actividades ilegales, incluida la prostitución, ante amenazas de daño físico o violencia real si ella no cumplía. Si la víctima no ganaba suficiente dinero para él, este se enojaba volvía violento contra ella. A la víctima nunca se le permitió quedarse con el dinero que ganaba. Hasta que finalmente ella buscó la ayuda de organizaciones externas para que le proporcionaran el soporte para reconstruir su vida y, en 2009, recibió una "Visa T" de no inmigrante, después de demostrarle al gobierno federal que fue víctima de tráfico humano. ${ }^{14}$

Para ser elegible, la víctima visa cumplió con la definición de formas graves de trata de personas, en virtud de la Ley de protección de las víctimas de trata de personas del año 2000 (TVPA), así como las posteriores Leyes de reautorización de protección a las víctimas de trata de personas de 2003, 2005 y 2008. Estas "formas graves de trata de personas" se definen como las siguientes: (1) trata de personas en las cuales un acto sexual comercial es inducido por la fuerza, el fraude o la coerción, o en el que la persona inducida a realizar dicho acto no ha cumplido los 18 años de edad; o (2) el reclutamiento, refugio, transporte, provisión u obtención de una persona para trabajo o servicios, mediante el uso de la fuerza, el fraude o la coerción con el fin de someterlos a servidumbre involuntaria, peonaje, servidumbre por deudas o esclavitud.

Por otro lado, a pesar de que a la víctima se le otorgó un estatus legal, sus antecedentes penales crearon una severa dificultad para ella. Por ejemplo, su trabajo como asistente de atención médica domiciliaria, que mantuvo durante aproximadamente cinco años, se vio comprometido cuando el Departamento de Salud hizo una verificación de antecedentes sobre ella y descubrió sus condenas penales. Como resultado de este descubrimiento, la víctima fue puesto en suspensión por el Departamento de Salud por primera vez en 2007. Con la asistencia del Proyecto de Trabajadoras Sexuales del Centro de Justicia Urbana, fue permitida para trabajar nuevamente después de haber impugnado con éxito la decisión del Departamento de Salud.

Debido a que la víctima se sentía vulnerable a que su experiencia fuera expuesta a futuros empleadores, creando más vergüenza, humillación y dificultades financieras. Ella presentó una moción para anular la condena penal de conformidad con la Ley de Procedimiento Penal § 440.10. Durante la vigencia del litigio, la Legislatura del Estado de Nueva York modificó la Ley de Procedimiento Penal, permitiendo a los tribunales de Nueva York, por primera vez, anular las condenas de los arrestados por delitos relacionados con la prostitución si eran víctimas de trata sexual en el momento del arresto. El Tribunal concedió la moción de la víctima al anular la sentencia de condena en cada uno de los seis casos de la víctima y desestimó todos los instrumentos acusatorios basados en el reconocimiento de que ella fue víctima de trata sexual y que fue forzada a actividades de prostitución y arrestada durante la Comisión de esta actividad ilegal. Por lo tanto, la aprobación de la nueva ley está dando a las víctimas de trata de personas un segundo cambio que merecen para una integración comunitaria saludable.

\section{Recursos para las Víctimas de Tráfico de Personas}

Los Servicios de Ciudadanía e Inmigración de los Estados Unidos (USCIS, por sus siglas en inglés) ayudan a proteger a las víctimas de trata de personas y otros delitos al proporcionarles asistencia de inmigración. Dado que este delito es también conocido como una forma de esclavitud moderna en la que los traficantes atraen a personas con falsas promesas de empleo y una vida mejor, tanto ellos como sus familiares también pueden ser víctimas de muchos otros tipos de crímenes en los Estados Unidos. Estos crímenes incluyen: violación, asesinato, homicidio, violencia doméstica y muchos otros. En este sentido, hay dos tipos de alivio de inmigración que USCIS brinda a víctimas de trata de personas y otros delitos: la Visa T de no inmigrante (Visa T) y la Visa U de no inmigrante (Visa U). ${ }^{15}$

14 Consulte la Ley de protección de víctimas de trata de personas de 2000, 8 CFR 214.11 - 22 Código de Estados Unidos $\S 7102$ (9) Víctimas extranjeras de formas graves de trata de personas.

15 American Civil Liberties Union, Trata de personas: Esclavitud moderna de mujeres inmigrantes en los Estados Unidos. Recuperado de https://www.aclu.org/other/human-trafficking-modern-enslavement-immigrant-women-united-states. 
La visa T proporciona alivio de inmigración a las víctimas del tráfico. Las víctimas pueden solicitar por sí mismas una Visa T si aceptan cooperar con la policía en una investigación criminal.

La visa $U$ se otorga a las personas que han sufrido abuso físico o mental como resultado de haber sido víctimas de un crimer mientras se encontraban en los Estados Unidos. Para ser elegible para una visa U, la víctima debe haber cooperado o estar dispuesta a cooperar en una investigación criminal.

Los destinatarios de estos alivios migratorios son elegibles para la obtención de un estatus de residente legal permanente.

En el área penal, los traficantes estan sujetos a multas y/o encarcelamiento como resultado de un proceso penal bajo la ley TVPA, la cual penaliza la trata con respecto al trabajo forzado, la servidumbre involuntaria, el peonaje y la esclavitud. La ley TVPA también tipifica como delito confiscar los documentos de una víctima para promover un delito de tráfico. Mientras que, en el área civil, las víctimas de trata podrán buscar una compensación económica por el sufrimiento causado presentando una demanda civil en contra de su traficante. ${ }^{16}$

\section{CONCLUSIÓN}

Casi todas las naciones del mundo, incluidos los Estados Unidos, están agobiadas por el aumento de los problemas de delincuencia económica, de salud pública, nacional y transnacional como resultado de la trata de personas. La falta de leyes y recursos para hacer cumplir la ley que abordan el tráfico, así como el hecho de que los gobiernos no reconozcan la gravedad del problema, contribuyen a la propagación del tráfico de personas. En este sentido, la promulgación de la Ley de Trata y Protección de Víctimas fue un paso crucial para erradicar este fenómeno a nivel internacional.

En todo el mundo, las mujeres sufren de trata de personas. Los bajos niveles de educación, la discriminación de género, la pobreza, el analfabetismo y la falta de oportunidades laborales afectan a las mujeres en gran número. Estas condiciones generan que las mujeres emigren, lo cual las hacen particularmente vulnerables a reclutadores sin escrúpulos que, a través de la fuerza, el fraude o la coerción, colocan a las mujeres en situaciones laborales en las que no consintieron y de las que no pueden escapar libremente.

En algunas ocasiones, cuando las autoridades descubren que una persona es víctima de tráfico, se les discrimina, encarcela y eventualmente deporta, debido a su estado migratorio. A la inversa, los traficantes escapan con un castigo ligero porque la ley es insuficiente para abordar los tipos de actividades en las que están involucrados.

\section{REFERENCIAS BIBLIOGRÁFICAS}

- Carole Angel y Lesley Orloff. Tráfico de personas y la T-Visa NIWAP (febrero de 2018) disponible en http://library.niwap.org/wp-content/uploads/2015/IMM-Man-Ch11-TraffickingTVisa.pdf

- Marley S. Weiss Trata de personas y trabajo forzoso: introducción, 131 ABA Journal Lab. \& Emp. Ley 1 (2015)

- Oficina de las Naciones Unidas contra la Droga y el Delito, Trata de Personas, disponible en www.unodc.org/unodc/en/human-trafficking/what-is-human-trafficking.html

- Convención de las Naciones Unidas contra la Delincuencia Organizada Transnacional y sus Protocolos (Nueva York, 2014) disponible en https://www.unodc.org/documents/treaties/ UNTOC/Publications/TOC\%20Convention/TOCebook-e.pdf

16 Servicios de Inmigración y Ciudadanía de los EE. UU. Víctimas de trata de personas, estatus de no inmigrante T disponible en https://www.uscis.gov/humanitarian/victims-human-trafficking-other-crimes/victims-human-trafficking-tnonimmigrant-status/questions-and-answers-victims-human-trafficking-t-nonimmigrant-status 
- Convención de las Naciones Unidas contra la Delincuencia Organizada Transnacional y sus Protocolos disponible en https://www.unodc.org/unodc/en/organized-crime/intro/UNTOC.html

- Ewelina U. Ochab. El crimen de más rápido crecimiento en el mundo (julio de 2017) disponible en https://www.forbes.com/sites/ewelinaochab/2017/07/29/the-worlds-fastestgrowingcrime/2/\#3d7c6ee06547

- OIT Económico del trabajo forzoso (mayo de 2014) disponible en http://www.ilo.org/global/ about-the-ilo/newsroom/news/WCMS_243201/lang--en/index.htm

- Oficina del Alto Comisionado de Derechos Humanos de las Naciones Unidas, Instrumentos Internacionales de Trata de Personas (agosto de 2014) disponible en http://www.ohchr.org/ Documents/Issues/Women/WRGS/OnePagers/IntInstrumentsconcerningTraffickingpersons_ Aug2014.pdf

- Oficina de Derechos Humanos del Alto Comisionado de las Naciones Unidas, Convención sobre los Derechos del Niño disponible en http://www.ohchr.org/EN/Professionallnterest/ Pages/CRC.aspx

- Organización Internacional del Trabajo, Convención sobre la prohibición y acción inmediata para la eliminación de las peores formas de trabajo infantil disponible en http://www.ilo.org/ dyn/normlex/en/f?p=NORMLEXPUB:12100:0 :: NO :: P12100_ILO_CODE: C182

- La Decimotercera Enmienda a la Constitución de los Estados Unidos dice en su totalidad: "Ni la esclavitud ni la involuntaria, excepto como castigo por un delito del cual la parte debe haber sido debidamente condenada, deben existir dentro de los Estados Unidos o en cualquier lugar sujeto a su jurisdicción".

- Departamento de Justicia, Departamento de Salud y Servicios Humanos y Departamento de Seguridad Nacional, Plan de Acción Estratégico Federal sobre Servicios para Víctimas de Trata de Personas en los Estados Unidos 5 2013-2017

- Proyecto Polaris, leyes federales vigentes disponibles en http://polarisproject.org/currentfederal-laws

- Resumen de acciones S.1311 - $115^{\circ}$ Congreso (2017-2018) disponible en https://www. congress.gov/bill/115th-congress/senate-bill/1311/actions

- Congress.Gov S.1312 - Ley de protección de víctimas de la trata de personas de 2017 disponible en: http://www.congress.gov/bill/115th-congress/senate-bill/1312/related-bills

- Carrie N. Barker, La influencia de la trata internacional de personas en las leyes de prostitución de los Estados Unidos: el caso de las leyes de expulsión 171 (Syracuse Law Review, febrero de 2012) disponible en http://lawreview.syr.edu/wp-content/uploads/2013 /03/K-Baker.pdf

- AlliancetoEndSlavery\&Trafficking(enerode2017)disponibleenhttps://endslaveryandtrafficking. org/summary-trafficking-victims-protection-act-tvpa-reauthorizations-fy-2017-2/

- Caroline Fish, Protegida, No Extraíble: Víctimas Extranjeras de Trata y las Políticas de Inmigración de la Administración Trump, 1 (The National Law Review) Noviembre de 2017, disponible en https://www.natlawreview.com/article/protected-not- extraíble-extranjero-tráficovíctimas-e-inmigración

- Línea directa nacional de tráfico de personas, tráfico de personas disponible en https:// humantraffickinghotline.org/type-trafficking/human-trafficking

- Proyecto Polaris, Los hechos disponibles en http://polarisproject.org/human-trafficking/facts

Fecha de Recepción: 14 de setiembre de 2018

Fecha de Aceptación 30 de octubre de 2018 